\title{
Impact of the Regulatory Framework for Transmission Investments on the Cost of Renewable Energy in the EU
}

\author{
Marcelo Saguan \\ Microeconomix \\ 5 rue du Quatre septembre, 75002 Paris, France \\ Leonardo Meeus \\ Vlerick Business School, Bolwerklaan 21, 1210 Brussels, Belgium \\ Florence School of Regulation, Robert Schuman Centre for Advanced Studies \\ European University Institute, Via Boccaccio 151, Florence, Italy
}

\begin{abstract}
Under the current regulatory frame in the EU, transmission planning is done at the national level to maximize national welfare, rather than European welfare. In this paper, we develop a competitive equilibrium model that calculates the impact of this imperfect regulatory framework on the cost of renewable energy. We apply the model to a power system with two interconnected zones, and find that the impact is case specific, but significant. We also find that the negative impact of national transmission planning on the cost of renewable energy is more significant in a state of the world in which Member States trade renewable energy, but that this negative effect is much smaller than the positive effect of renewable energy trade between Member States. We conclude that the imperfect regulatory framework for transmission investment is a significant cost for renewable energy in the EU, but that it should not stop Member States from trading renewable energy.
\end{abstract}

\section{Keywords}

Renewable energy; transmission network; electricity market; modeling

\section{Introduction}

The EU objective is to rely on renewable energy sources for $20 \%$ of the energy consumed in 2020 , and the efforts to achieve this objective have been shared among Member States with binding national targets (EU, 2009a). The burden sharing agreement has been partly based on the renewable energy potential of the different countries, and partly based on their economic power. This implies that there are opportunities to trade renewable energy to reduce the cost of achieving the national targets (Admundsen and Nese, 2009), which is also allowed by the regulatory framework: Norway and Sweden are the first to organize cross-border renewable energy trade using a common market for green certificates. Aune et al. (2011) found that the cost of achieving the national renewable energy targets for 2020 could be reduced by almost 70\%, and EC (2008), Capros et al. (2009) and Ecofys et al. (2011) consider that the annual savings could be up to $€ 10$ billion. 
However, these studies assume that the transmission investments that are required to enable this generation cost reduction will follow. The importance of transmission investments to avoid spilling renewable energy and to reduce the cost of backup capacity in a power system with increasing share of renewable energy has also been underlined in the recent debate around the EU Roadmap 2050 (Meeus et al., 2012). The electricity industry association (Eurelectric, 2010) for instance envisages an electricity generation mix with $40 \%$ renewable energy in 2050. The study considers 241 interconnections between countries, concluding that the desired increase of interconnection capacity would be $40 \%$ by 2030 (from 179 to $253 \mathrm{GW}$ ), after which the grid capacity would remain stable until 2050. The European Climate Foundation (ECF, 2010) considers electricity generation mixes with up to $80 \%$ renewable energy in 2050. Their energy system analysis focuses on 15 corridors, and calculates the desired increase of the total capacity of these corridors by 2050 with different demand flexibility assumptions. The desired increase of the corridors is $388 \%$ (from $34 \mathrm{GW}$ to 166 ) in the $80 \%$ renewable energy scenarios without improvement in demand flexibility, which reduces to $274 \%$ in scenario with $20 \%$ improvement of demand flexibility.

The problem is that these transmission investments will not necessarily materialize under the current regulatory framework in the EU. Transmission planning in Europe is mainly done at the national level to maximize national welfare. The National Regulatory Authorities that have to approve the investments are indeed mandated to take care of national interests. This can result in suboptimal transmission investments because cross-border projects that are beneficial for Europe, but not for all the involved Member States, can be blocked as Member States can veto or delay projects that are partly developed on their territories.

The main contribution of this paper is to propose a model that can analyze the relevance of this problem in the EU context. Building on the work of Buijs et al. (2011), Buijs and Belmans (2011), Drondorf et al. (2010), and especially Sauma and Oren (2006, 2009), we develop a competitive equilibrium model that captures the four states of the world that are relevant in this context: a situation with no trade versus perfect trade of renewable energy across borders in combination with national versus international transmission planning. We apply the model to a power system with two interconnected zones to illustrate the relevance of suboptimal transmission investments for the cost of renewable energy. The example also provides insights into the sensitivities of the results to the differences between the zones in terms of their access to renewable energy sources.

The paper is organized into 3 sections. Section 1 details the four states of the world that are analyzed in the paper. Section 2 explains how the four states of the world have been modeled. Section 3 presents the results of the numerical example. The paper finally concludes with the main insights that we take away from this modeling exercise.

\section{States of the world}

Electricity wholesale market integration across national borders is an ongoing process in the EU (Glachant and Lévêque, 2009). The process is driven by cooperation among market operators, which is referred to as the coupling of markets (Meeus et al., 2005; 2011a; 2011b). For the purpose of this 
paper, we will assume the market is already perfectly integrated so that we can focus on comparing two states of the world for renewable trade and transmission planning (Table 1). ${ }^{1}$

Table 1: Matrix representation of the four states of the world considered in this paper

\begin{tabular}{|l|c|c|c|}
\hline \multicolumn{2}{|c|}{} & \multicolumn{2}{c|}{ Renewable energy trade } \\
\cline { 3 - 4 } & No trade & Perfect trade \\
\hline \multirow{2}{*}{ Transmission planning } & National & $\begin{array}{c}\text { 1 } \\
\text { (current state of the world) }\end{array}$ & 2 \\
\cline { 2 - 4 } & International & 3 & 4 \\
\hline
\end{tabular}

\subsection{Renewable energy trade}

Every country in Europe has a binding national renewable energy target, which have been set at EU level to share the burden of achieving the EU objective that $20 \%$ of the energy consumption in 2020 should be based on renewable energy. The EU framework for renewable energy support schemes includes the possibility for member states to trade renewable energy to comply with their national targets, but they can also choose to develop their domestic renewable energy sources. We consider two extreme states of the world for renewable energy trade: no trade and perfect trade.

In the first state of the world, there is no renewable energy trade. This is the current situation between most EU Member States, as indicated in the recently submitted National Renewable Energy Action Plans (EC, 2011). Only Italy and Luxembourg intend to import a small share of the renewable energy they need to comply with their binding national targets. In the second state of the world, there is perfect renewable energy trade. This is the current situation between Sweden and Norway, who decided to implement a common mechanism, a unified green certificates market.

Note that the current situation with almost no trade in renewable energy in Europe can be explained by the existence of local benefits for the development of renewable energy technologies and nonharmonized national support schemes. Renewable development policies are indeed about proving public support to renewable energy technologies. Some of the benefits are global, such as the reduction in greenhouse gas emissions; other benefits are more local, such as the reduced dependence on imported fossil fuels and the creation of green jobs and technology industries (Lund, 2009). Various instruments are being used, from so-called feed-in tariffs to green certificates systems and mandatory obligations regarding the share of renewables in the energy production sectors (Aune et al., 2008; Haas et al., 2011; IEA, 2009). To be able to trade renewable energy, member states need to harmonize their support schemes, or at least make them compatible.

\subsection{Transmission planning}

We consider two extreme states of the world for transmission planning: national planning and international planning. As discussed in the introduction, the current state of the world in EU is

\footnotetext{
${ }^{1}$ Note that we do not model climate change policies, such as the European Emission Trading Scheme: it would not modify our main results; including this scheme would imply studying other policy interactions that are out of the scope of this paper, but have already been treated by, for instance, Linares et al (2008).
} 
national transmission planning. The third energy liberalization package and the energy infrastructure package include first steps towards a more international perspective for transmission planning in the EU. The third energy liberalization package, for instance, introduced the Ten Year Network Development Plan that tries to improve the coordination between the different national transmission plans (ENTSOE, 2012). The energy infrastructure package goes a step further by encouraging Member States to design innovative cross-border cost allocation agreements that can potentially unblock some projects with a benefit for Europe, but without a strong national interest for all involved parties (EU, 2013). However, without additional intervention, planning will continue to aim at maximizing national rather than European welfare (Buijs et al., 2011; Buijs and Belmans, 2011).

\section{Modeling the states of the world}

We model a three-stage decision process, as in the work of Sauma and Oren $(2006,2009)$. In the first stage, the transmission capacity is decided, followed by the generation investments in the second stage, and the production and consumption schedules in the third stage. At each stage, the reaction of the next stage is anticipated. A first novelty of the model is that it also includes a two-zone system managed by two different transmission system operators regulated by a different national regulatory authority that jointly decide on the capacity of the interconnector between them. Buijs et al. (2011), Buijs and Belmans (2011) and Drondorf et al. (2010) already studied multi-zone systems with different transmission planning objectives, but they did it in a two-stage decision process without generation investment. A second novelty of the model is that it includes the possibility to integrate renewable energy support schemes. Linares et al (2008) already studied this type of schemes, but they did it in a single zone system, without considering transmission investments.

In order to focus on imperfections in transmission and renewable policies, we assume competitive behavior of electricity generators. This introduces a supplementary difference with respect to the Sauma and Oren $(2006,2009)$ framework, which includes oligopolistic (Cournot) behavior for electricity generators. We could have represented the model as an optimization program, but we have instead chosen for a competitive equilibrium representation as it is closer to the functioning of electricity markets, and it can easily be extended.

In this section, we first introduce the characteristics of the two-zone power system that will be modeled, to then discuss each of the three decision stages.

\subsection{Power system characteristics}

In what follows, we introduce the characteristics of demand, generation, and transmission in the two-zone power system that is modeled in this paper (Figure 1). 


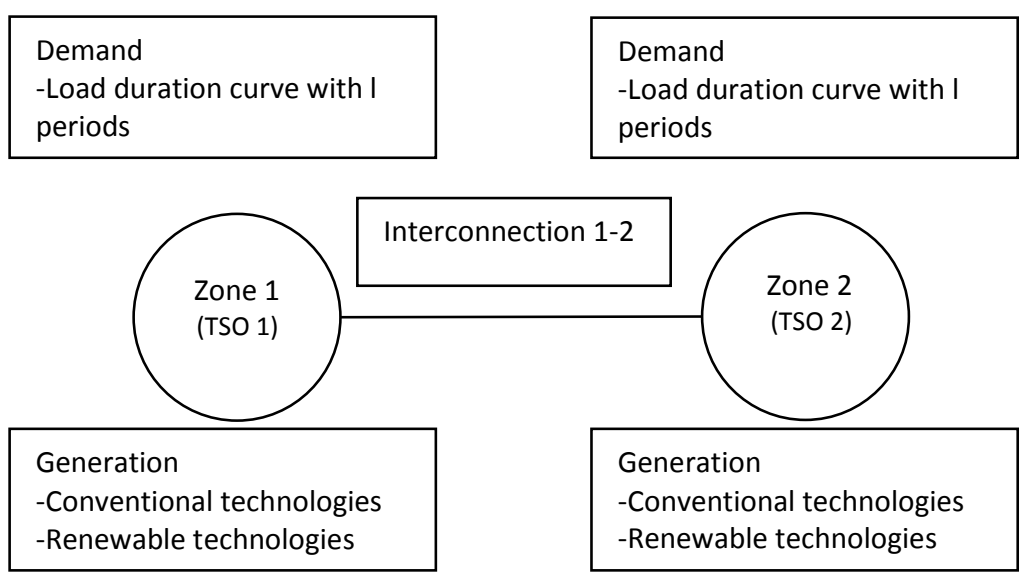

Figure 1: two-zone electricity system

First is the electricity demand. We represent demand by a load duration curve to simplify the analysis, but it does imply that we do not take into account the short-term variability of demand and renewable energy sources so that backup costs are underestimated. In each zone $n$, the curve consists of $L$ different periods $l$ with a certain duration $t_{l}$ (measured in hours) and a level of demand $d_{l, n}$ (expressed in MW's) (see Figure 2). Demand is inelastic, but the model does include the possibility of having shortages. The unsatisfied demand in period $l$ (in $\mathrm{MW}$ ) in zone $n$ is $z_{l, n}$. In hours with shortages, the price is fixed to the so-called Value of Lost Load (VOLL). Note that in our model $V O L L$ is an exogenous parameter set at the conventional value between 1000 and $10000 € / \mathrm{MWh}$.



Figure 2: load duration curve 
Second is generation, which is represented by different types of generation technologies. There are $s$ types of conventional generation technologies and $r$ types of renewable energy technologies in each zone $n$. The cost of each technology is described with two parameters: the variable operating cost (in $€ / \mathrm{MWh}$ ), which is $V C_{s, n}$ for the conventional generation technologies and $V C R_{r, n}$ for the renewable energy technologies, and the annual investment capacity cost (in $€ / \mathrm{MW}$.year), which is $C C_{s, n}$ for the conventional generation technologies and $C C R_{s, n}$ for the renewable energy technologies. $g_{s, n}$ and $g R_{r, n}$ are the installed generation capacities of the conventional and renewable generation technologies types, with $x_{l, s, n}$ and $x R_{l, r, n}$ the energy they produce in a period $l$. We assume that conventional capacity is $100 \%$ available throughout the year (i.e., no unforeseen outages and no need to stop for maintenance), while we do apply an availability factor to renewable generation. $a R_{l, r, n}$ is this factor, which is given for a certain type of renewable technology, in a certain zone, and in a certain period.

Third is transmission, which is the line interconnecting the two zones. The line has a certain transmission capacity Tcap (in MW) that caps the energy that can be transferred between the zones. We assume that the interconnector does not have losses or other variable cost. The annualized cost of expanding the transmission capacity is given by CTcap (in €/MW.year).

\subsection{Electricity market}

In the third stage of the model, consumption and production decisions are made for a given set of generation capacities $\left(g_{s, n}, g R_{r, n}\right)$, and a given interconnection capacity (Tcap). The market operator matches demand and supply in each zone and period, taking into account the interconnection capacity constraint, and determining the electricity market prices. In what follows, we explain how this has been modeled. Note that we use complementarity notation to represent optimality conditions in this paper. ${ }^{2}$

\subsubsection{Demand}

Consumers valorize electricity consumption $\left(d_{l, n}-z_{l, n}\right)$ at VOLL level and buy it at ElectPrice $_{l, n}$. The following equation represents the optimality conditions that maximize the net surplus of consumers in each zone $n$ and period $l$.

Equation (1): VOLL - ElectPrice $_{l, n}>0 \perp z_{l, n}>0 \quad \forall l, n$

Equation 1 ensures that in periods and zones when demand can be satisfied $\left(z_{l, n}=0\right)$, the electricity price will be lower than the value of lost load (VOLL), while in periods and zones with lost load $\left(z_{l, n}>\right.$ $0)$, the electricity price is set at the level of the VOLL.

\subsubsection{Generation}

We model a competitive equilibrium, which means generators do not behave strategically to increase prices; they simply bid their variables costs. As a result, prices reflect the variable costs of the last plant that is needed to match demand, respecting of course their (available) capacity constraints $\left(g_{s, n}\right.$ and $\left.a R_{l, r, n} * g R_{r, n}\right)$. The optimality conditions for the generators can then be expressed by the following equations, with $x_{l, s, n}, x R_{l, r, n}$ the level of production of the conventional and renewable generators, respectively:

\footnotetext{
${ }^{2}$ The symbol $\perp$ indicates complementarity and means that only one of the two conditions should apply. For instance the expression $x>0 \perp F(x)>0$ implies that: $x>0$ and $F(x)=0$; or $F(x)>0$ and $x=0$.
} 
Equation (2): $V C_{s, n}+y_{-} g_{l, s, n}-$ ElectPrice $_{l, n}>0 \perp x_{l, s, n}>0 \quad \forall l, s, n$

Equation (3): $V C R_{r, n}+y_{-} g R_{l, r, n}-$ ElectPrice $_{l, n}>0 \perp x R_{l, r, n}>0 \quad \forall l, r, n$

Equation (4): $g_{s, n}-x_{l, s, n}>0 \quad \perp y_{-} g_{l, s, n}>0 \quad \forall l, s, n$

Equation (5): $a R_{l, r, n} * g R_{r, n}-x R_{l, r, n}>0 \quad \perp y_{-} g R_{l, r, n}>0 \quad \forall l, r, n$

Equations 2 and 3 ensure that electricity prices are high enough to cover the generator's variable cost in periods where the generator produces $\left(x_{l, s, n}, x R_{l, r, n}>0\right.$ and therefore $V C_{s, n}+y_{-} g_{l, s, n}-$ ElectPrice $_{l, n}=0, V C R_{r, n}+y_{-} g R_{l, r, n}-$ ElectPrice $\left._{l, n}=0\right)$. The equations also ensure that the electricity prices are lower than the generator's variable costs in periods where the generator does not produce $\left(x_{l, s, n}, x R_{l, r, n}=0\right.$ and therefore $V C_{s, n}+y_{-} g_{l, s, n}-$ ElectPrice $_{l, n}>0, V C R_{r, n}+$ $y_{-} g R_{l, r, n}-$ ElectPrice $\left._{l, n}>0\right)$. Note that $y_{-} g_{l, s, n}$ and $y_{-} g R_{l, r, n}$ are the dual variables of the generation capacity constraints, they are nonnegative and represent scarcity rents for each technology and period.

Equations 4 and 5 ensure that production complies with the (available) generation capacity constraints. For conventional generation (equation 4), the generation capacity constraint ensures that production is equal or less than installed generation capacity (we assume that conventional generation is $100 \%$ available over the year). For renewable generation (equation 5 ), installed capacity is adjusted by an availability factor $\left(a R_{l, r, n}\right)$.

Combined, the above equations (2-5) also ensure that prices can only go above the variable cost of a certain generator, if this generator is producing at its maximum (i.e., dual variables of generation capacity constraints are positive, $\left.y_{-} g_{l, s, n}, y_{-} g R_{l, r, n}>0\right)$. It is in these periods that the generator accumulates scarcity rents to recover investment costs, as will be discussed below.

\subsubsection{Market operator}

We suppose that the market operator arbitrates perfectly between the two zones, while respecting the limited interconnection capacity Tcap and the energy balance in each period. The following equations represent the corresponding optimality conditions:

Equation (6): $\sum_{s, n} x_{l, s, n}+\sum_{r, n} x R_{l, r, n}+\sum_{n} z_{l, n}-\sum_{n} d_{l, n}>0 \quad \perp y_{-} b n e g_{l}>0 \quad \forall l$

Equation (7): $-\sum_{s, n} x_{l, s, n}-\sum_{r, n} x R_{l, r, n}-\sum_{n} z_{l, n}+\sum_{n} d_{l, n}>0 \quad \perp y_{-} b p o s_{l}>0 \quad \forall l$

Equations 6 and 7 ensure that demand matches production in each period, and if it does not that this demand is registered as unsatisfied demand. $y_{-} b n e g_{l}$ and $y_{-} b p o s_{l}$ are the dual variables of the balance constraint and their difference represents the marginal cost of production at the slack bus (zone 1 following our convention).

Equation (8): $\sum_{n, s} x_{l, s, n}+\sum_{n, r} x R_{l, r, n}+\sum_{n} z_{l, n}-\sum_{n} d_{l, n}+$ Tcap $>0 \perp y_{-}$fpos $_{l}>$ $0 \quad \forall$ land $n=2$

Equation (9): $-\sum_{n, s} x_{l, s, n}-\sum_{n, r} x R_{l, r, n}-\sum_{n} z_{l, n}+\sum_{n} d_{l, n}+$ Tcap $>0 \perp y_{-} f_{n e g}>$ $0 \quad \forall$ land $n=2$ 
Equations 8 and 9 ensure that what is exchanged between the two zones stays within the limits of the interconnection capacity on the border. $y_{-} f p o s_{l}$ and $y_{-} f n e g_{l}$ are the dual variables of the interconnection transmission capacity constraint for the positive and negative flow direction, respectively. These dual variables are positive when the flow is equal to the transmission capacity Tcap (i.e., the transmission line is congested).

The electricity price in each zone and period, ElecPrice $_{l, n}$, is determined with the following expression, using the dual variables of equations 6 to 9:

ElecPrice $_{l, n}=y_{-}$bneg $g_{l}-y_{-}$bpos $_{l}-(n-1)\left(y_{\text {fpos }_{l}}-y_{\text {fneg }}\right) \forall l, n$

Note that the prices of the zones diverge if the dual variables of equations 8 and 9 are positive (i.e., the transmission line is congested) because the dual variables of equations 6 and 7 are the same for the two zones.

\subsection{Generation investment}

In the second stage of the model, generators decide their production capacity in each zone, taking into account the given interconnection capacity between the zones (Tcap ). In what follows, we explain how this investment decision has been modeled, first for conventional generation and then for renewable generation.

\subsubsection{Conventional technologies}

We model a competitive equilibrium, which implies that generators invest up to the point where the scarcity rents match the investment cost of the technology. The investment decision can then be expressed by the following equation:

Equation (11): $C C_{s, n}-\sum_{l} y_{-} g_{l, s, n} t_{l}>0 \perp g_{s, n}>0 \quad \forall s, n$

$C C_{s, n}$ (in $€ / M W$.year) is the annual investment capacity cost of conventional technology $s$ in zone $n$. Equation 11 ensures that a conventional technology is only chosen by generators $\left(g_{s, n}>0\right)$, if the scarcity rent that this technology will accumulate in a year of production is high enough to recuperate the annual investment capacity cost of this technology type.

\subsubsection{Renewable energy technologies}

In our model, we only consider renewable energy technologies are not yet competitive. Without extra support, their investment costs are too high to be recuperated with scarcity rents. But, the technology can receive public support in the model, which is an additional source of income that modifies the investment decision as follows:

Equation (12): $C C R_{r, n}-\sum_{l} y_{-} g R_{l, r, n} a R_{l, r, n} t_{l}-\sum_{l} \operatorname{RenPremium}_{n} t_{l}>0 \perp g R_{r, n}>0 \quad \forall r, n$

$C C R_{s, n}$ (in $€ / \mathrm{MW}$.year) is the annual investment capacity cost of renewable energy technology $r$ in zone $n$. Equation 12 ensures that a renewable energy technology is chosen by generators $\left(g R_{r, n}>0\right)$,

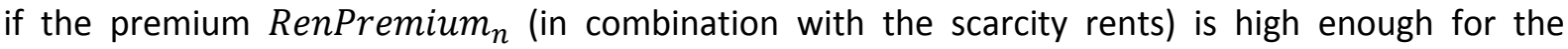
investor to recuperate the investment cost of this technology type. 
The premium in turn depends on the state of the world, which is perfect trade in renewable energy versus no trade. For the state of the world without trade in renewable energy between zones, the following equations need to be added to the model ${ }^{3}$.

Equation (13): $\sum_{l, r} x R_{l, r, n} t_{l}-$ RenTarget $_{n}>0 \perp y_{-}$RenTarget $_{n}>0 \quad \forall n$

Equation (14): RenPremium ${ }_{n}=y_{-}$RenTarget $_{n} \forall n$

Equation 13 ensures that the production from renewable energy technologies matches the renewable energy target in each zone $\left(\right.$ RenTarget $\left._{n}\right)$. Equation 14 sets the zonal premium equal to the dual variable of the equation that forces the model to reach the zonal renewable energy target $\left(y_{-}\right.$RNtarget $\left.{ }_{n}\right)$ so that the model achieves the target.

For the state of the world with perfect trade in renewable energy between zones, the following equations need to be added to the model:

Equation (15): $\sum_{l, n, r} x R_{l, r, n} t_{l}-$ RenTargetTrade $>0 \perp y_{\text {RenTargetTrade }}>0$

Equation (16): RenPremium ${ }_{n}=y_{\text {RenTargetTrade- }}$

Equation 15 ensures that the total production from renewable energy technologies matches the combined target of the two zones (RenTargetTrade $=\sum_{n}$ RenTarget $_{n}$ ) so that the target of one zone can be achieved with investments in another zone. Equation 16 sets the zonal premium equal to the dual variable of the equation ( $y_{-}$RGtarget) that forces the model to reach the renewable energy target.

\subsection{Transmission investment}

In the first stage of the model, transmission planning leads to a decision regarding the transmission capacity between the two zones. We model two states of the world, which are national versus international transmission planning.

In the state of the world with international transmission planning, the transmission capacity (Tcap') is chosen to maximize the total welfare of the two zones, subject to the above discussed competitive equilibrium model (1)-(16).

Tcap' $=\operatorname{Max}_{\text {Tcap }} \sum_{n}$ Welfare $_{n}$ s.t. Equations (1) - (16)

In the state of the world with national transmission planning, each zone is investing in its part of the interconnector to maximize the zonal welfare:

Tcap $_{n}{ }_{n}=\operatorname{Max}_{\text {Tcap }}$ Welfare ${ }_{n}$ s.t. Equations (1) - (16) $\quad \forall n$

As the two parts of the interconnector are organized in a serial manner, the capacity between the two zones will be defined by the minimum of the two investment decisions:

$\operatorname{Tcap}^{\prime}=\min \left(\operatorname{Tcap}_{1}{ }_{1} ; \operatorname{Tcap}_{2}{ }_{2}\right)$.

\footnotetext{
${ }^{3}$ Note that the premium is calculated from a common RE target and it will be paid to all RE technologies, as in a market for green certificates. The model could easily integrate other support schemes, such as feed-in premium with specific targets for each technology, but this is out of the scope of this paper.
} 
Tcap' is a Nash equilibrium because the two zones do not have an incentive to deviate from this position. Indeed, once the zone with the lower optimal transmission capacity has decided to build this level of capacity, the best strategy for the other zone is to build the same level of capacity. If it builds less capacity, its national welfare will decrease. If it builds more capacity, its transmission cost will increase without any positive effect in welfare because the interconnection capacity will be set by the minimal value (the capacity in the other zone).

In both states of the world, the zonal welfare can be computed as the sum of consumer, producer surplus, and congestion revenue, minus transmission costs. This can be done based on the outputs of the model for a given level of interconnection transmission capacity (Tcap). Inline with current practice, we assume that each zone pays for the assets on its own territory, and we also assume that congestion revenues are shared on the same basis, which is fifty-fifty in our example.

$$
\begin{aligned}
& \text { Welfare }_{n}=\text { Consumer surplus }_{n}+\text { producer surplus } \text { s }_{n}+\frac{\text { congestion revenue }}{2} \\
& -\frac{\text { transmission cost }}{2}
\end{aligned}
$$

Note finally that the model assumes that electricity consumers pay RE subsidies, which is typically the case in Europe, and which implies that the subsidy is a welfare transfer from consumers to RES producers. ${ }^{4}$ In the state of the world without renewable energy trade between the two zones, the transfer (RES subsidy $y_{n}$ ) is equal to the zonal premium ( $€ / \mathrm{MW}$ per year) times the renewable energy capacity (MW) installed in that zone and the number of hours in a year. In the state of the world with perfect renewable energy trade between the two zones, we assume that the total transfer is shared equally between the two zones.

\section{Numerical example}

In this section, we first introduce the data, and then discuss the simulation results.

\subsection{Data}

The data is representative for a typical power system. Here, we introduce how demand, generation, transmission, the renewable energy targets, and the renewable energy sources are represented in our numerical example.

Demand is the same in each simulation, and equal in both zones. The following load duration curve has been used: $d_{l}=22,000 \mathrm{MW}-1.37 \mathrm{H}$ ( $\mathrm{H}$ being the number of hours between 0 and 8760 ), which has also been used by Joskow (2008). In this paper, this curve has been modeled with 10 periods of equal size (i.e., 876 hours each); and VOLL has been fixed to $4000 € / \mathrm{MWh}$. The cost parameters of conventional generation are also the same in each simulation, and equal in both zones. The example has two conventional generation technologies, i.e. base and peak load plants. The conventional generators have an annualized capacity cost of 300,000 (base) and 80,000 (peak) €/MW per year, and a variable cost of 20 (base) and 80 (peak) $€ / M W h$. The transmission cost is also the same in each simulation, and equal in both zones. Following Realisegrid (2010), the annualized cost of transmission capacity is set to $7000 € / \mathrm{MW}$ per year. The renewable energy targets vary between simulations, but

\footnotetext{
${ }^{4}$ The alternative would be that taxpayers pay the RE subsidies, so that the partial equilibrium model we have presented here would need to be extended to become a general equilibrium model.
} 
they are always assumed to be equal in both zones. The targets are expressed as the percentage of consumption that has to be covered by renewable energy, and we consider targets of $30 \%, 40 \%$ and $50 \%$, like the national renewable energy targets of EU Member States.

The renewable energy sources are the focus of our analysis. We simulate three cases (Figure 3) to test the sensitivity of the results to zonal differences in the investment cost of renewable energy technology, and the characteristics of the renewable energy sources in terms of their average availability and the correlation of this availability with demand. The differences are inspired by the typically differences between photovoltaic and onshore wind technology, see for instance Joskow (2010), Burger (2013), or EIA (2013). In case 1, the renewable energy sources of both zones are not correlated with demand, but their average availability and their investment cost are different. In case 2 , the investment cost and the average availability of the renewable energy sources are the same in both zones, but they have an opposite correlation with demand (renewable energy sources in zone 1 is positively correlated with demand whereas the opposite is true in zone 2). In case 3 , the investment costs are different, the average availability of the renewable energy sources is different, and they have an opposite correlation with demand. Note that case 3 is closest to reality, but case 1 and 2 allow us to test which differences have a biggest impact on the results.
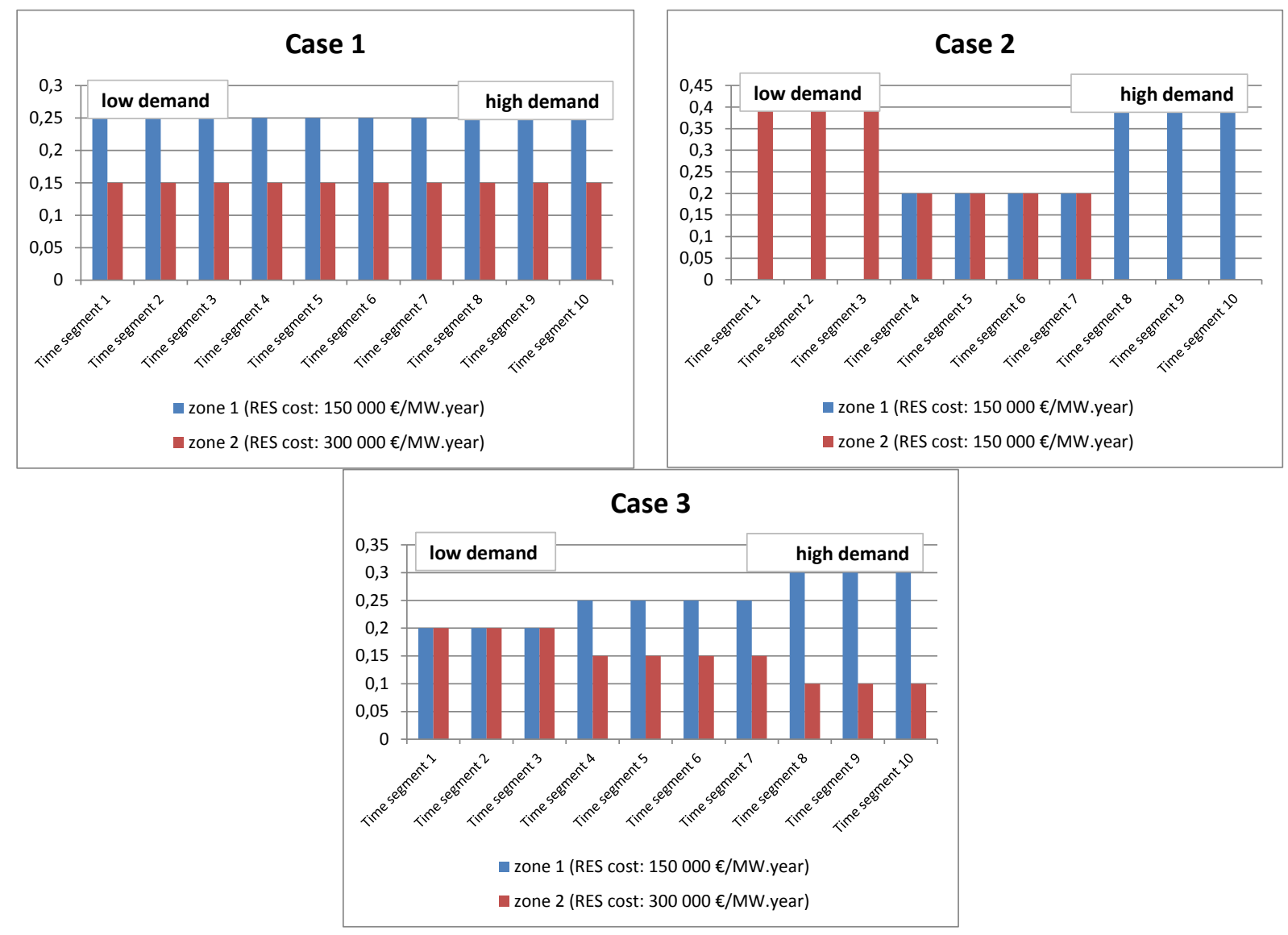

Figure 3: Three cases with different renewable energy sources

\subsection{Simulation results}

We first provide an overview, and then discuss the results of one of the simulations in more detail to show how the model works. 


\subsubsection{Overview of the simulations}

Transmission capacity can reduce the spilling of renewable energy so that the same target can be reached with fewer investments in (expensive) renewable energy capacity. Transmission capacity can also reduce the need for backup capacity so that demand can be satisfied with fewer investments in conventional generation capacity. Yet, these effects do not play if there is no spilling (i.e., available renewable energy is always lower than demand), or if there is spilling, but the two zones spill renewable energy in the same periods. The same applies to the need for back up capacity.

Table 2 indeed illustrates that the optimal capacity between the two zones is sometimes zero. In the state of the world without renewable energy trade, the optimal capacity is zero in case 1 and 3, but not in case 2 , which is the case in which the zones differ the most in terms the availability of their renewable energy sources in different periods. In other words, case 2 is characterized by a strong complementarity between the renewable energy sources in the two zones. In the state of the world with renewable energy trade, transmission is more important because renewable energy investments can be concentrated in one zone, which can cause spilling.

Table 2: Importance of transmission

\begin{tabular}{|c|c|c|c|c|}
\hline \multicolumn{3}{|c|}{ Renewable energy } & \multicolumn{2}{|c|}{ Transmission capacity at equilibrium } \\
\hline State of the world & Availability & Target & International planning & National planning \\
\hline \multirow{9}{*}{ No trade } & \multirow{3}{*}{ Case 1} & $30 \%$ & 0 & 0 \\
\hline & & $40 \%$ & 0 & 0 \\
\hline & & $50 \%$ & 0 & 0 \\
\hline & \multirow{3}{*}{ Case 2} & $30 \%$ & 2000 & 750 \\
\hline & & $40 \%$ & 3750 & 2250 \\
\hline & & $50 \%$ & 5500 & 4000 \\
\hline & \multirow{3}{*}{ Case 3} & $30 \%$ & 0 & 0 \\
\hline & & $40 \%$ & 0 & 0 \\
\hline & & $50 \%$ & 0 & 0 \\
\hline \multirow{9}{*}{ Perfect trade } & \multirow{3}{*}{ Case 1} & $30 \%$ & 0 & 0 \\
\hline & & $40 \%$ & 2250 & 0 \\
\hline & & $50 \%$ & 5500 & 0 \\
\hline & \multirow{3}{*}{ Case 2} & $30 \%$ & 5000 & 3000 \\
\hline & & $40 \%$ & 6750 & 4750 \\
\hline & & $50 \%$ & 8250 & 6250 \\
\hline & \multirow{3}{*}{ Case 3} & $30 \%$ & 0 & 0 \\
\hline & & $40 \%$ & 250 & 0 \\
\hline & & $50 \%$ & 2250 & 0 \\
\hline
\end{tabular}

The regulatory framework for transmission investments can, of course, only have an impact in simulations where the optimal transmission capacity is non-zero. Table 2 illustrates that in each of these simulations, national transmission planning results in suboptimal (lower) transmission investments. As Illustrated in Table 3, this has an impact on the cost of renewable energy, which is 
the additional cost of serving load and reaching the renewable energy target that is imposed on the model. The impact is significant in each simulation with cost increases of $1 \%$ up to $89 \%$. Table 3 also illustrates that the impact is strongly case specific, depending on the ambition of the renewable energy target, as well as, the renewable energy sources differences between the zones.

Table 3: impact of transmission investment on the cost of renewable energy in M€

\begin{tabular}{|c|c|c|c|c|c|c|}
\hline \multicolumn{3}{|c|}{ Renewable energy } & \multicolumn{2}{|c|}{$\begin{array}{l}\text { Cost of renewable energy } \\
\text { for different type of } \\
\text { transmission planning }\end{array}$} & \multirow{2}{*}{\multicolumn{2}{|c|}{$\begin{array}{l}\text { Impact of transmission } \\
\text { planning on cost of } \\
\text { renewable energy }\end{array}$}} \\
\hline $\begin{array}{c}\text { State of the } \\
\text { world }\end{array}$ & Availability & Target & $\begin{array}{c}\text { International } \\
\text { planning }\end{array}$ & $\begin{array}{l}\text { National } \\
\text { planning }\end{array}$ & & \\
\hline \multirow{9}{*}{ No trade } & \multirow{3}{*}{ Case 1} & $30 \%$ & 8302 & 8302 & 0 & $0 \%$ \\
\hline & & $40 \%$ & 11069 & 11069 & 0 & $0 \%$ \\
\hline & & $50 \%$ & 13837 & 13837 & 0 & $0 \%$ \\
\hline & \multirow{3}{*}{ Case 2} & $30 \%$ & 2838 & 2966 & 128 & $5 \%$ \\
\hline & & $40 \%$ & 3792 & 3978 & 186 & $5 \%$ \\
\hline & & $50 \%$ & 4745 & 5081 & 336 & $7 \%$ \\
\hline & \multirow{3}{*}{ Case 3} & $30 \%$ & 8460 & 8460 & 0 & $0 \%$ \\
\hline & & $40 \%$ & 11280 & 11280 & 0 & $0 \%$ \\
\hline & & $50 \%$ & 14100 & 14100 & 0 & $0 \%$ \\
\hline \multirow{9}{*}{$\begin{array}{l}\text { Perfect } \\
\text { trade }\end{array}$} & \multirow{3}{*}{ Case 1} & $30 \%$ & 1330 & 1330 & 0 & $0 \%$ \\
\hline & & $40 \%$ & 1789 & 1887 & 97 & $5 \%$ \\
\hline & & $50 \%$ & 2256 & 4262 & 2007 & $89 \%$ \\
\hline & \multirow{3}{*}{ Case 2} & $30 \%$ & 1262 & 1790 & 527 & $42 \%$ \\
\hline & & $40 \%$ & 2216 & 2700 & 485 & $22 \%$ \\
\hline & & $50 \%$ & 3169 & 3728 & 560 & $18 \%$ \\
\hline & \multirow{3}{*}{ Case 3} & $30 \%$ & 857 & 857 & 0 & $0 \%$ \\
\hline & & $40 \%$ & 1144 & 1153 & 9 & $1 \%$ \\
\hline & & $50 \%$ & 1444 & 2102 & 659 & $46 \%$ \\
\hline
\end{tabular}

Note finally that the table also shows that effects of renewable energy trade are of a different order of magnitude than the effects of transmission planning. The renewable energy cost increase due to lack of renewable energy trade between the two zones goes up to $570 \%$ in case 3 with a renewable energy target of $50 \%$, in a state of the world with national transmission planning. In the state of the world with renewable energy trade, all renewable energy investments in case 3 go to zone 1 where it is much cheaper to build, where less capacity needs to be built to achieve the same target because the renewable energy is more available on average, and where less conventional backup capacity is needed for renewable energy because it is positively correlated with demand.

\subsubsection{Details of one simulation}

In what follows, we discuss the results of one of the simulations in Table 3 in more detail to show how the model works. We will illustrate the impact of transmission investment on: total and zonal welfare (Figure 4); prices (Figure 5); generation investments (Figure 6); renewable energy subsidy 
(figure 7) and the different welfare components (figure 8). We focus on case 2 with a renewable energy target of $40 \%$ in the state of the world without renewable energy trade.

Figure 4 illustrates the impact of transmission investment on total and zonal welfare. There are three key observations. First observation is that total welfare increases steeply until the transmission capacity reaches $3750 \mathrm{MW}$, after which it slowly decreases. The initial increase is mainly due to an increase of welfare in zone 1, and a smaller increase of welfare in zone 2 . The slow decrease for higher levels of transmission investment is caused by the cost of transmission. Second observation is that the welfare in zone 2 is significantly lower than in zone 1 because the renewable energy source of zone 2 is negatively correlated with demand, while the renewable energy source of zone 1 is positively correlated with demand in case 2 . Third observation is that zonal welfare in both zones increases for increasing investment in transmission until the cross-border capacity reaches $2250 \mathrm{MW}$, after which the zonal welfare of zone 2 starts to decrease. In other words, national transmission planning will result in $2250 \mathrm{MW}$ transmission capacity, while international planning would result in $3750 \mathrm{MW}$.

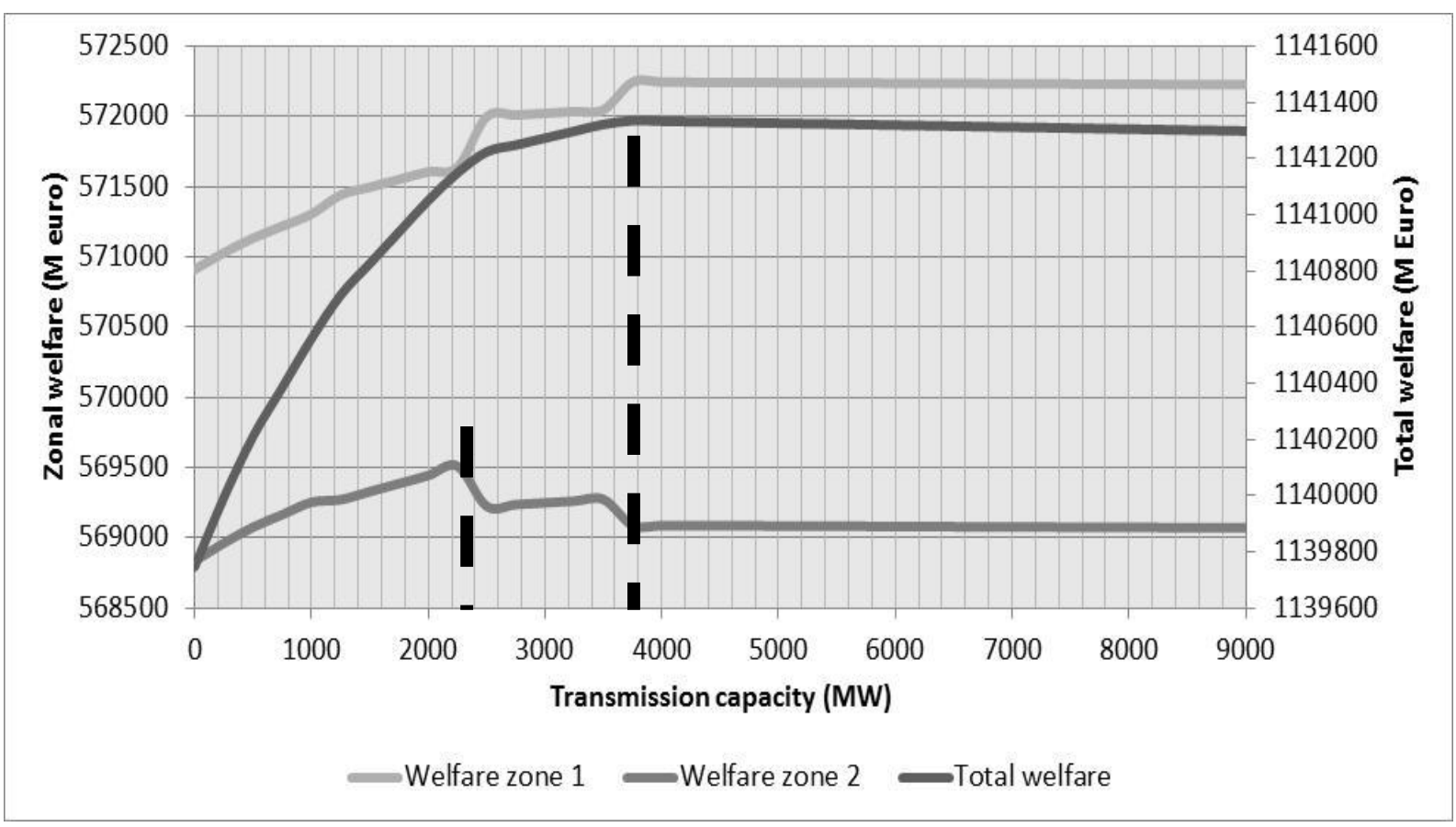

Figure 4: Impact of transmission investment on zonal welfare

Figure 5 illustrates the impact of transmission investment on prices. There are two key observations. First observation is that investment in transmission increases the electricity price in both zones over the full range of 0 to $3750 \mathrm{MW}$ transmission capacity. One might expect that prices would increase in the exporting zone and decrease in the importing zone, but there are two explanations for the price increase in the importing zone. Firstly, there is a price reduction in some periods (e.g., periods with low demand in zone 1), which is outweighed by price increase in other periods (e.g., periods with high demand in zone 1), and we only illustrate the weighted average price. Secondly, the classic expectation is derived from a static model without investment, and as we discuss below the changing investment behavior in our model explains this price phenomenon. The second observation is that investment in transmission decreases the renewable energy premium price over the full range of 0 to 
$3750 \mathrm{MW}$ transmission capacity. The increasing electricity prices indeed increase the income for renewable energy generators, which in turn reduces their need for subsidies.

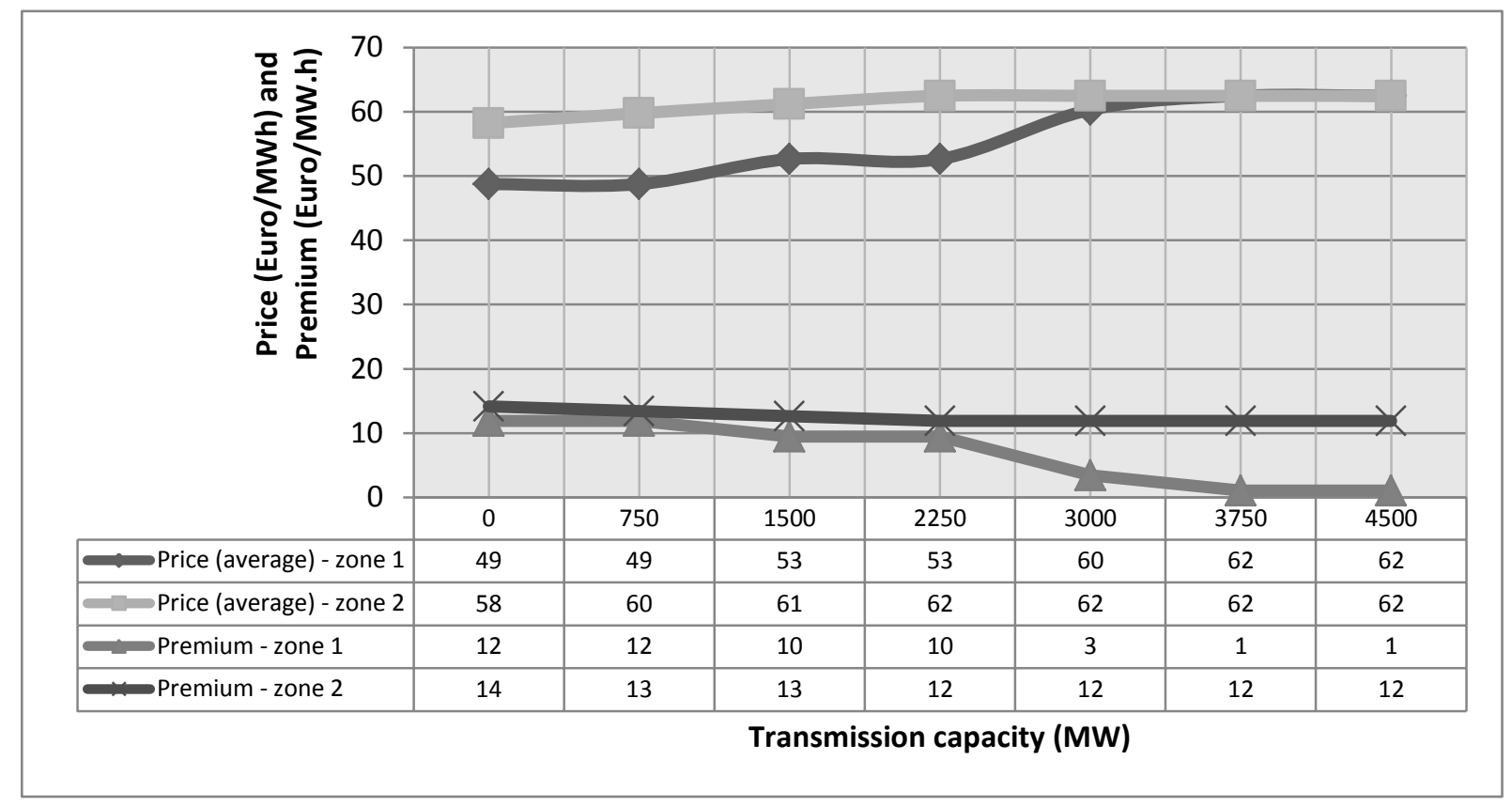

Figure 5: Impact of transmission investment on prices (i.e. electricity market price and renewable energy premium price)

Figure 6 illustrates the impact of transmission investment on generation investment. Note that the model calculates with steps of $250 \mathrm{MW}$. We illustrate less steps to increase the readability of the figure, and choose $750 \mathrm{MW}$ so that 2250 and $3750 \mathrm{MW}$ are included, which are the capacities corresponding to the investment in the national and international transmission planning policy case, respectively. There are three key observations. First observation is that investment in transmission reduces the total installed generation capacity from around $105 \mathrm{GW}$ to $97 \mathrm{GW}$ for an optimal transmission investment of $3750 \mathrm{MW}$. The reduction in installed generation capacity mainly takes place in zone 2 that has the less favorable renewable energy source. Indeed, in zone 2: renewable energy capacity reduces with more than $3 \mathrm{GW}$; conventional peak capacity reduces by almost $3 \mathrm{GW}$; while conventional base capacity increases with just over $1 \mathrm{GW}$. In zone 1, on the contrary: renewable energy capacity remains unchanged; conventional peak capacity reduces by almost $2 \mathrm{GW}$; and conventional base capacity reduces by less than half a GW. Second observation is that investment in transmission reduces the spilling of renewable energy because less renewable energy capacity is needed to achieve the same volume of renewable energy. Zone 2 indeed has a renewable energy source that is negatively correlated with demand so that renewable energy is spilled in hours with low demand if there is not enough transmission capacity to export it to the other zone. The increase in cross-border transmission capacity then implies that zone 2 can export its renewable energy to zone 1 in hours of low demand. Note that for zone 1 it implies that less conventional generation production is needed to cover demand. Third key observation is that we can now also explain the increase in electricity prices in Figure 5 . Transmission capacity reduces the investment in 
renewable energy capacity and partially also in conventional generation capacity. This generation investment optimization implies a load factor increase for conventional generators. As the variable cost of conventional generators is higher than the cost of renewable energy technologies, electricity prices increase with increasing investment in transmission.

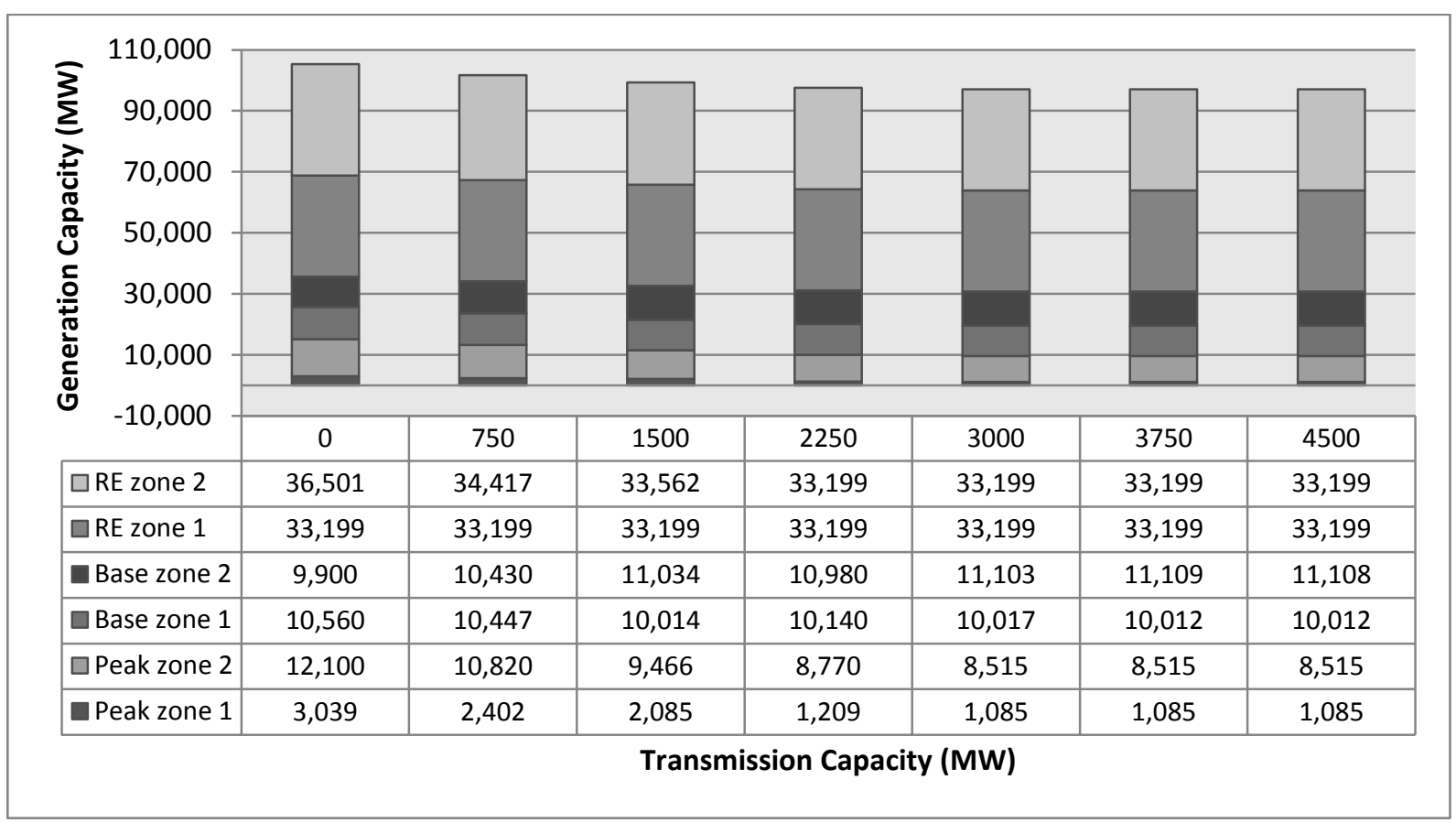

Figure 6: Impact of transmission investment on the installed generation capacity mix

Figure 7 illustrates the impact of transmission investment on the renewable energy subsidy in zone 1 and zone 2. Investment in transmission decreases the renewable energy subsidy in both zones, but stronger in zone 1 than in zone 2. There is a double effect: the renewable energy premium prices decrease (see Figure 5: $€ / M W$ per year); and the installed renewable energy capacities decrease (Figure 6: MW). 


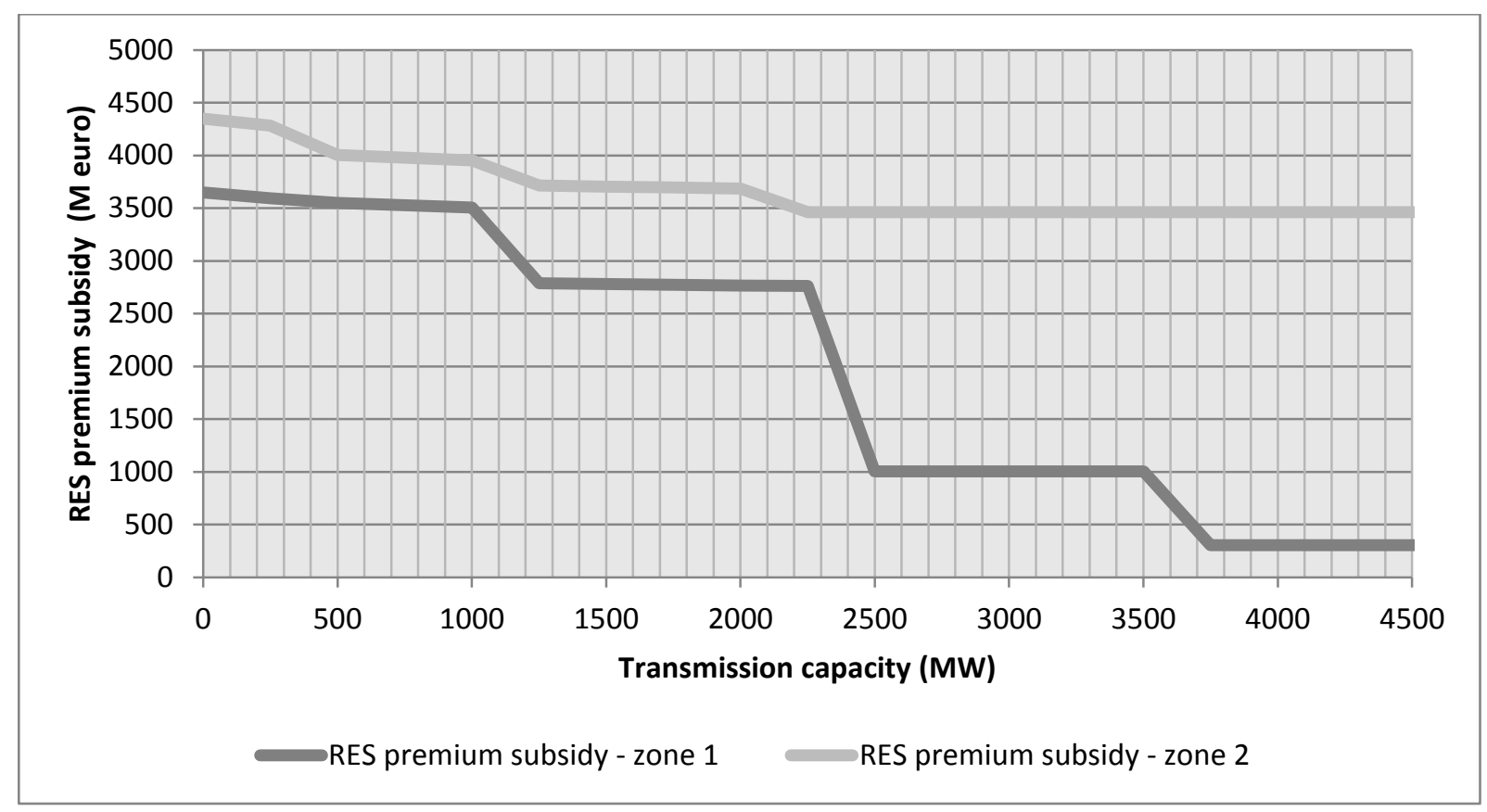

Figure 7: Impact of transmission investment on RES subsidy

Figure 8 illustrates the impact of transmission investment on the different welfare components, i.e. consumer surplus, congestion revenue and transmission cost. Note also that we do not illustrate producer surplus because we model a competitive equilibrium in which producer surplus always equals the generation investment costs so that there is no welfare effect. There are four key observations. First observation is that investment in transmission increases consumer surplus in both zones, but stronger in zone 1 than in zone 2 . Note that this increase is mainly caused by a reduction in the RES subsidy level (Figure 7), which dominates the increase in electricity prices (Figure 5), while the same volume is consumed because there is no lost load in our simulations. Second observation is that investment in transmission first increases congestion revenues then decrease them to zero, which is the point at which arbitrage equalizes the zonal market prices so that the transmission line stops being congested. Note that both zones have the same congestion revenue because we suppose that they share the total revenue, which is the standard practice in Europe. Third observation is that investment in transmission increases the transmission costs, which are shared equally between both zones. Fourth observation is that we can now also explain Figure 4: the welfare of both zones initially increases because they both benefit from a decreasing renewable energy subsidy and an increase of congestion revenue, which dominates the increase in prices and in transmission costs; at around $2250 \mathrm{MW}$ transmission capacity zone 2 stops benefitting from this renewable energy subsidy reduction, so that increasing transmission investment beyond this point only increases the costs of zone 2, without generating any benefit. 


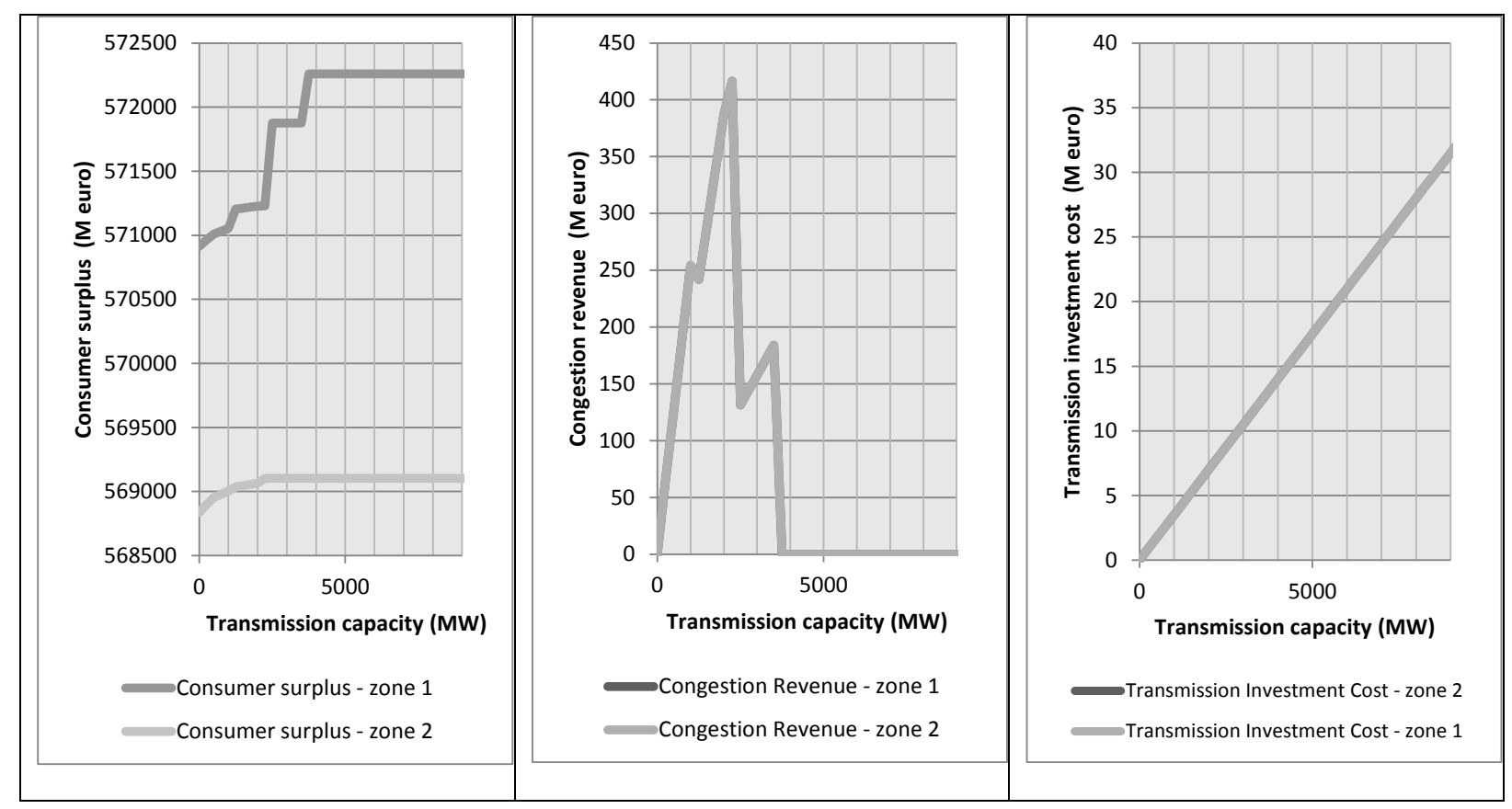

Figure 8: Impact of transmission investment on the welfare components

\section{Conclusions}

In this paper, we analyzed the cost of renewable energy in four states of the world, i.e. with versus without renewable energy trade between zones, and with national transmission planning versus international transmission planning. We developed a novel competitive equilibrium model for this purpose, and applied it to a power system with two interconnected zones. We assumed that the zones are identical in terms of their demand, access to conventional generation technologies, and transmission costs, so that we could focus our sensitivity analysis on the differences between the two zones in terms of their access to renewable energy sources. We therefore constructed three cases. In one case, we assumed that the zones have different renewable energy investment costs, as well as, different availability, and correlation with demand. In the other two cases, we introduced fewer differences to see which are more relevant.

The conclusion is that the costs of renewable energy are the highest in the current state of the world in the EU without renewable energy trade between Member States, and with national transmission planning. The potential benefits of renewable energy trade are well known, and some Member States have already started to trade, but less progress has been made on the regulatory framework for transmission investments. The negative impact of suboptimal transmission investments on the cost of renewable energy has also not been considered in other studies, or models. We find that this impact is case specific, but significant. We also find that the impact is more significant in a state of the world where Member States trade renewable energy. However, the positive effect of renewable energy trade in our simulations outweighs the negative effect of suboptimal transmission investments. In other words, the imperfect regulatory framework for transmission investments is a significant cost for renewable energy in the EU, but it should not stop Member States from trading renewable energy to already reduce that cost.

Note finally that the novel competitive equilibrium model introduced in this paper provides a good indication of the cost of renewable energy in the four states of the world that needed to be analyzed, 
but the model, of course, also has its limitations. The representation of demand with load duration curves, for instance, underestimates the cost of renewable energy. A possible extension of the model would therefore be to integrate the short-term variability of demand and renewable energy sources as well as various source of flexibility (e.g., generation ramping, demand response). The model could also be improved by including uncertainty, alternative support schemes with separate targets for different renewable energy technologies, and more innovative ways of sharing transmission and renewable costs and benefits. The model could finally be extended to include strategic behavior of generators.

\section{Acknowledgements}

This paper has benefited from comments from two anonymous reviewers and the editor. We are also grateful to Denny Ellerman for inviting us to the renewable energy modeling seminar of the climate policy unit he directs at the European University Institute in Florence, which has inspired us to work on this topic. We thank the discussants William D'haeseleer, Jean-Michel Glachant, Ignacio Perez Arriaga, Mario Ragwitz, Pippo Ranci, and Christian von Hirschhausen, and the seminar participants for their detailed comments. We also thank Patrik Buijs, Erik Delarue and Pedro Linares for sharing their GAMS code, which has been our starting point to develop the model in this paper.

\section{References}

Amundsen, E.S., Nese, G., 2009. Integration of tradable green certificate markets: what can be expected? Journal of Policy Modeling 31, 903-922.

Aune, F. R., R. Golombek, S. A. C. Kittelsen and K. E. Rosendahl, 2008. Liberalizing European Energy Markets. An Economic Analysis. Cheltham, UK, Edward Elgar Publisher.

Aune, F. R., Dalen, H. M., Hagem, C., 2010. Implementing the EU renewable target through green certificate markets. Energy Economics, In Press, Corrected Proof, Available online 22 July 2011.

Buijs, P., Belmans, R., 2011. Transmission investments in a multilateral context. Accepted for publication in IEEE transactions in power systems.

Buijs, P., Meeus, L., Belmans, R., 2011. Modeling bi-level games in transmission investments. . IAEE International Conference. Stockholm, Sweden, 19-23 June 2011.

Burger, B., 2013. Electricity production from solar and wind in Germany in 2012. FRAUNHOFER INSTITUTE FOR SOLAR ENERGY SYSTEMS ISE.

Capros, P., Mantzos, L., Papandreou, V., Tasios, N., 2008. Model-based Analysis of the 2008 EU Policy Package on Climate Change and Renewables. Report to European Commission - DG ENV.

Drondorf, G., Egerer, J., Herrmann, E., Grieger, M., Mueller, C., Schaefer, P., Schoenfelder, R., Schultz, K., Siegel, A., 2010. Welfare Based Incentives for Cooperative and Non-Cooperative Strategies in Cross-Border Transmission Expansion Games. Seminar paper.

EC, 2008. European Commission, Impact Assessment, Document accompanying the Package of Implementation measures for the EU's objectives on climate change and renewable energy for 2020. SEC(2008) 85 C6-0041/08. Available at: http://www.europarl.europa.eu/registre/docs _autres_institutions/commission_europeenne/sec/2008/0085/COM_SEC\%282008\%290085_EN.pdf. 
EC, 2011. Renewable Energy: Progressing towards the 2020 target. COM(2011)31 final. Brussels, 31 January 2011.

ECF, 2010. European Climate Foundation, Roadmap 2050 - A practical guide to a prosperous lowcarbon Europe. http://www.roadmap2050.eu/.

Ecofys, Ernst \& Young, Fraunhofer ISI, TU Vienna, 2011. Financing Renewable Energy in the European Energy Market. Report commissioned by the European Commission. Available at: http://ec.europa.eu/energy/renewables/studies/doc/renewables/2011_financing_renewable.pdf.

EIA 2013. Updated Capital Cost Estimates for Utility Scale Electricity Generating Plants. U.S. Department of Energy, U.S. Energy Information Administration. April 2013.

ENTSO-E, 2012. ENTSO-E Ten-Year Network Development Plan 2012. July 2012.

EU, 2009a. European Union, Directive 2009/28/EC of the European Parliament and of the Council of 23 April 2009 on the promotion of the use of energy from renewable sources and amending and subsequently repealing Directives 2001/77/EC and 2003/30/EC. Available at: http://eurlex.europa.eu/LexUriServ/LexUriServ.do?uri=OJ:L:2009:140:0016:0062:en:PDF.

EU, 2009b. Third package, including the Directive 2009/72/EC concerning common rules for the internal market in electricity; Regulation (EC) No 714/2009 on conditions for access to the network for cross-border exchanges in electricity; and Regulation (EC) No 713/2009 establishing an Agency for the Cooperation of Energy Regulators.

EU, 2013. Regulation (EU) No 347/2013 on guidelines for trans-European energy infrastructure and repealing Decision No 1364/2006/EC and amending Regulations (EC) No 713/2009, (EC) No 714/2009 and (EC) No 715/2009.

Eurelectric, 2010. Union of the Electricity Industry, Power Choices - Pathways to carbon-neutral electricity in Europe by 2050. Available at: http://www2.eurelectric.org/content/default.asp? PagelD=708.

Glachant, J.-M., Lévêque, F., Eds., 2009. Electricity Reform in Europe. Edward Elgar Publishers, 2009.

Haas, R., Resch, G., Panzer, C., Busch, S., Ragwitz, M., Held, A., 2011. Efficiency and effectiveness of promotion systems for electricity generation from renewable energy sources - Lessons from EU countries. Energy. 36(4): 2186-2193.

IEA, 2009. International Energy Agency, Deploying renewables - principles for effective policies. International Energy Agency, OECD/IEA 2009 Paris.

Joskow, P., 2008. Capacity payments in imperfect electricity markets: need and design. Utilities Policy, Vol.16, No. 3, pp. 159-170.

Joskow, P., 2010. Comparing the costs of intermittent and dispatchable electricity generating technologies. Discussion draft, September 27, 2010 (R2).

Linares, P., Santos, F.J., Ventosa, M., Lapiedra, L.., 2008. Incorporating oligopoly, CO2 emissions trading and green certificates into a power generation expansion model. Automatica, 44(6), 16081620.

Lund, P. D., 2009. Effects of energy policies on industry expansion in renewable energy. Renewable Energy, 34, 53-64. 
Meeus, L., Purchala, K., Belmans, R., 2005. Development of the internal electricity market in Europe, Electricity Journal, 18(6), pp. 25-35.

Meeus, L., 2011a. Why (and how) to regulate Power Exchanges in the EU market integration context. Energy Policy, 39(3), pp. 1470-1475.

Meeus, L., 2011b. Implicit auctioning on the Kontek Cable: Third time lucky? Energy Economics, 33(3), 413-418.

Meeus, L., Azevedo, I., Marcantonini, C., Glachant, J.-M., Hafner, M., 2012. EU 2050 low-carbon energy future: visions and strategies. Electricity Journal, 25(5), pp. 57-63.

Realisegrid, 2010. EU FP7 project "Research methodologies and technologies for the effective development of pan-European key grid infrastructures to support the achievement of a reliable, competitive and sustainable supply", realisegrid.erse-web.it.

Sauma, E.E., Oren, S.S., 2006. Proactive planning and valuating of transmission investments in restructured electricity markets. Journal of Regulatory Economics, 30(3), 358-387.

Sauma, E.E., Oren S.S., 2009. Do generation firms in restructured electricity markets have incentives to support social-welfare-improving transmission investments? Energy Economics, 31(5), 676-689. 


\section{Appendix 1: Nomenclature}

Sets

\begin{tabular}{|c|l|}
\hline$s$ & Types of plant - conventional technologies (e.g., coal, gas, etc) \\
\hline$r$ & Types of plant - renewable technologies (e.g., wind, PV, etc) \\
\hline$l$ & Period of load duration curve \\
\hline$n$ & zones (e.g., France, Germany) \\
\hline
\end{tabular}

\section{Parameters}

\begin{tabular}{|c|c|c|c|}
\hline Type & Name & Description & Unit \\
\hline \multirow[t]{3}{*}{ Demand } & VOLL & Value of lost load & $€ / \mathrm{MWh}$ \\
\hline & $d_{l, n}$ & demand in period I in zone $\mathrm{n}$ & MW \\
\hline & $t_{l}$ & duration of period I (the sum of $t(I)$ is equal to 8760 ) & Hours \\
\hline \multirow[t]{5}{*}{ Generation } & $C C_{s, n}$ & $\begin{array}{l}\text { annual investment capacity cost for conventional } \\
\text { technologies }\end{array}$ & [€\MW.year] \\
\hline & $V C_{s, n}$ & variable cost for conventional technologies & [€\MWh] \\
\hline & $C C R_{r, n}$ & annual investment capacity cost for renewables & [€\MW.year] \\
\hline & $V C R_{r, n}$ & variable cost for renewable & {$[€ \backslash \mathrm{MWh}]$} \\
\hline & $a R_{r, l, n}$ & $\begin{array}{l}\text { Availability factor for renewable } r \text { in zone } n \text { and for } \\
\text { period I }\end{array}$ & \\
\hline \multirow[t]{2}{*}{ Transmission } & CCT & annual capacity cost transmission & (€/MW.year) \\
\hline & Tcap & transmission capacity of interconnector & $\mathrm{MW}$ \\
\hline \multirow[t]{2}{*}{$\begin{array}{l}\text { Renewable } \\
\text { policy }\end{array}$} & RenTarget $_{n}$ & $\begin{array}{l}\text { minimal annual renewable energy to be produced in } \\
\text { zone } \mathrm{n}\end{array}$ & MWh/year \\
\hline & RenTargetTrade & $\begin{array}{l}\text { minimal annual renewable energy to be produced in } \\
\text { both zones }\end{array}$ & MWh/year \\
\hline
\end{tabular}

\section{Variables}

\begin{tabular}{|c|c|c|c|}
\hline Type & Name & Description & Unit \\
\hline \multirow[t]{5}{*}{$\begin{array}{l}\text { (Primal) } \\
\text { Variables }\end{array}$} & $x_{l, s, n}$ & $\begin{array}{l}\text { generation of conventional plant type } \mathrm{s} \text { at the segment } \\
\text { period I and zone } \mathrm{n} \text { during one hour }\end{array}$ & MW \\
\hline & $g_{s, n}$ & $\begin{array}{l}\text { maximal generation output (capacity) of conventional } \\
\text { plant type } s \text { in zone } n\end{array}$ & MW \\
\hline & $x R_{l, s, n}$ & $\begin{array}{l}\text { generation of renewable plant type } r \text { at the segment } \\
\text { period I and zone } n \text { during one hour }\end{array}$ & MW \\
\hline & $g R_{r, n}$ & $\begin{array}{l}\text { maximal generation output (capacity) of renewable } \\
\text { plant type } r \text { in zone } n\end{array}$ & MW \\
\hline & $Z_{l, n}$ & $\begin{array}{l}\text { unsatisfied demand in period I in zone } \mathrm{n} \text { during one } \\
\text { hour }\end{array}$ & MW \\
\hline \multirow[t]{4}{*}{$\begin{array}{l}\text { (Dual) } \\
\text { variables }\end{array}$} & $y_{-} g_{l, s, n}$ & $\begin{array}{l}\text { dual variable for maximal production constraint for } \\
\text { each plant } \mathrm{s} \text { at period I and zone } \mathrm{n} \text { (this variable is }>0 \\
\text { when constraint of conventional capacity is active) }\end{array}$ & $€ / \mathrm{MWh}$ \\
\hline & $y_{-} g R_{l, r, n}$ & $\begin{array}{l}\text { dual variable for maximal production constraint for } \\
\text { each plant } r \text { at period I and zone } n \text { (this variable is }>0 \\
\text { when constraint of renewable capacity is active) }\end{array}$ & $€ / \mathrm{MWh}$ \\
\hline & $y_{-} b p o s_{l}$ & $\begin{array}{l}\text { dual variable for positive balance constraint (this } \\
\text { variable is }>0 \text { when balance constraint is active in one } \\
\text { direction) }\end{array}$ & $€ / \mathrm{MWh}$ \\
\hline & $y_{-} b n e g_{l}$ & dual variable for negative balance constraint (this & $€ / \mathrm{MWh}$ \\
\hline
\end{tabular}




\begin{tabular}{|c|c|c|c|}
\hline & & \multicolumn{2}{|l|}{$\begin{array}{l}\text { variable is }>0 \text { when balance constraint is active in the } \\
\text { other direction) }\end{array}$} \\
\hline & $y_{-} f p o s_{l}$ & $\begin{array}{l}\text { dual variable for positive flow constraint of } \\
\text { interconnector (this variable is }>0 \text { when there is } \\
\text { congestion in line l in one direction) }\end{array}$ & $€ / M W h$ \\
\hline & $y_{-} f_{n e g}$ & $\begin{array}{l}\text { dual variable for negative flow constraint of } \\
\text { interconnector (this variable is }>0 \text { when there is } \\
\text { congestion in interconnector in the other direction) }\end{array}$ & $€ / \mathrm{MWh}$ \\
\hline & $y_{-}$RenTargetTrade & $\begin{array}{l}\text { dual variable for renewable energy global constraint or } \\
\text { renewable energy premium (this variable is }>0 \text { when } \\
\text { there is not enough renewable generation, i.e., } \\
\text { renewable energy premium has a positive price) }\end{array}$ & €/MW.h \\
\hline & $y_{-}$RenTarget $_{n}$ & $\begin{array}{l}\text { dual variable for renewable energy constraint on zone } \\
n \text { or renewable energy premium in zone } n \text { (this variable } \\
\text { is }>0 \text { when there is not enough renewable generation } \\
\text { in zone } n \text {, i.e., renewable energy premium in zone } n \\
\text { has a positive price) }\end{array}$ & $€ / M W . h$ \\
\hline \multirow{7}{*}{$\begin{array}{l}\text { (Output) } \\
\text { variables }\end{array}$} & ElectPrice $_{l, n}$ & Electricity price at zone $n$ for demand period I & $€ / \mathrm{MWh}$ \\
\hline & RenPremium $_{n}$ & Renewable energy premium at zone $n$ & $€ / M W . h$ \\
\hline & Consumer Surplus $_{n}$ & National consumer surplus at zone $n$ & $€ /$ year \\
\hline & Producer Surplus $_{n}$ & National producer surplus at zone $n$ & $€ /$ year \\
\hline & Congestion Revenue & Congestion revenue of interconnection & $€ /$ year \\
\hline & RES subsidy & Renewable subsidy at zone $n$ & $€ /$ year \\
\hline & Welfare $_{n}$ & National Welfare at zone $n$ & $€ /$ year \\
\hline
\end{tabular}

